\title{
Corresponding-States Correlation and Prediction of Third Virial Coefficients for a Wide Range of Substances
}

\author{
D. X. Liu $^{1}$ and H. W. Xiang ${ }^{1,2}$
}

Received October 30, 2002

\begin{abstract}
An extended corresponding-states model is developed that is capable of correlating and predicting the third virial coefficients for a wide range of substances. The present method only requires substance-dependent parameters, such as the critical temperature, critical volume, acentric factor, and aspherical factor, which are based on the simple extended corresponding-states principle. Comparisons with experimental data and existing models show that the present model is more general in that it not only is equivalent to the existing method for nonpolar gases, but also can represent the third virial coefficients of polar substances.
\end{abstract}

KEY WORDS: corresponding-states principle; critical parameters; polar molecules; thermodynamic properties; virial coefficients; virial equation.

\section{INTRODUCTION}

Virial coefficients are related to the intermolecular potential. When combined with the ideal-gas heat capacity, all of the equilibrium vaporphase thermodynamic properties can be calculated from the virial coefficients. Therefore, the virial coefficients provide a critical bridge between macroscopic and microscopic properties, and accurate knowledge of the virial coefficients is of great significance. To date, although many measurements have been extensively obtained for the second virial coefficient, the experimental data for the third virial coefficient are much less, especially for polar and associating substances. This mainly results from the

\footnotetext{
${ }^{1}$ Center for Molecular Science, Institute of Chemistry, Chinese Academy of Sciences, Zhongguancun, Haidian, Beijing 100080, People's Republic of China.

${ }^{2}$ To whom correspondence should be addressed. E-mail: hwxiang@iccas.ac.cn
} 
difficulties and relatively large uncertainties in the experimental measurements. Therefore, it is helpful to predict the third virial coefficient using suitable theoretical models.

\section{SURVEY}

Many theoretical methods have been developed to calculate the third virial coefficient. Intermolecular potential models, such as the LennardJones (12-6) potential [1], the square-well potential [1, 2], and the Stockmayer potential $[3,4]$ have been used to calculate the third virial coefficient. The Lennard-Jones $(12,6)$ potential and the square-well potential can satisfactorily represent the virial coefficients for nonpolar molecules [5-7]. The Stockmayer potential can be used to calculate the third virial coefficients of polar compounds [3, 4, 8]. In addition, Weber adopted Kohler's idea that described the molecules as hard convex bodies $[9,10]$ and successfully predicted the third virial coefficients of some refrigerants $[11,12]$. Although these methods have had some successes, fewer methods can reliably predict and correlate the third virial coefficient of nonpolar, polar, and strongly associating substances, for example, some calculations for water are quite complicated. Compared with the above methods, a corresponding-states correlation is of some interest.

Several correlations for the third virial coefficients dependent on the corresponding-states principle (CSP) are available in the literature. Chueh and Prausnitz proposed a two-parameter corresponding-states correlation, but it was only applied to nearly spherical and nonpolar molecules $[9,13]$. Pope et al. [14] gave another correlation, which is, however, restricted to compounds with an acentric factor up to 0.1 over narrow temperature ranges. De Santis and Grande [15] proposed a general predictive correlation, but it requires the dipole polarizability of a molecule and Bondi's molecular volume [16] in addition to the critical volume, critical temperature, and acentric factor of the compound. Recently, Orbey and Vera [17] gave a simple correlation for estimating the third virial coefficients of nonpolar substances; Bosse and Reich [18] proposed a semi-empirical correlation for the third virial coefficients of nonpolar gases. Besher and Lielmezs [19] calculated the third virial coefficient using a cubic equation of state for polar substances as well as for nonpolar substances. However, these three methods were not generalized, and the dipole moment with an adjustable exponent was used as a fit parameter for the last method and was complicated for polar substances. In this work, based on the simple extended CSP, the present correlation is a more useful way to correlate and predict the third virial coefficients of nonpolar and polar compounds. 


\section{THE SIMPLE EXTENDED CORRESPONDING-STATES PRINCIPLE (SE-CSP)}

The CSP of Pitzer et al. [20, 21] has been successfully applied to a wide range of nonpolar substances, but it does not work well for polar and associating species $[22,23]$. A recently developed extended correspondingstates principle has proved to be an effective method to describe polar compounds [24-26]. In the simple extended corresponding-states principle (SE-CSP), an extended corresponding-states parameter, $\theta=\left(Z_{\mathrm{c}}-0.29\right)^{2}$, was introduced in a similar way to the acentric factor [24-26]. It was defined to consider the deviation of the critical compressibility factor, $Z_{\mathrm{c}}$, of a real nonspherical molecule from spherical molecules. The extended corresponding-states parameter is an independent characteristic parameter for a real molecule, which significantly improves the ability of corresponding states to reflect the behavior of polar substances.

\section{DEVELOPMENT}

To predict and correlate the third virial coefficient $C$ from the corresponding-states principle, it is important to select a reference equation. In this work, we choose the corresponding-states correlation of Orbey and Vera [17]. Using the critical temperature $T_{c}$, the critical pressure $p_{\mathrm{c}}$, and the acentric factor $\omega$ as adjustable parameters, the empirical correlation of Orbey and Vera [17] is

$$
\frac{C p_{\mathrm{c}}^{2}}{\left(R T_{\mathrm{c}}\right)^{2}}=f C_{\left(T_{\mathrm{r}}\right)}^{(0)}+\omega f C_{\left(T_{\mathrm{r}}\right)}^{(1)}
$$

where $R$ is the universal gas constant, $T_{\mathrm{r}}=T / T_{\mathrm{c}}$ is the reduced temperature, and $T$ is the temperature.

In the critical compressibility factor, $Z_{\mathrm{c}}=p_{\mathrm{c}} M / R \rho_{\mathrm{c}} T_{\mathrm{c}}$ with $\rho_{\mathrm{c}}$ being the critical density, we have

$$
V_{\mathrm{c}}=\frac{Z_{\mathrm{c}} R T_{\mathrm{c}}}{p_{\mathrm{c}}}
$$

where $V_{\mathrm{c}}=1 / \rho_{\mathrm{c}}$. The values of $T_{\mathrm{c}}, p_{\mathrm{c}}$, and $\rho_{\mathrm{c}}$ for each substance are listed in Table I. Equation (1) was modified and extended to include $Z_{\mathrm{c}}$ and $\theta$, making the equation more general and capable of predicting properties of polar fluids. The values of $\theta$ and the acentric factor $\omega$ are also listed in Table I. The new equation is

$$
\frac{C}{V_{\mathrm{c}}^{2}}=f_{\left(T_{\mathrm{r}}\right)}^{(0)}+\omega f_{\left(T_{\mathrm{r}}\right)}^{(1)}+\theta f_{\left(T_{\mathrm{r}}\right)}^{(2)}
$$


Table I. Molar Mass, Critical Parameters, Acentric Factor, and Aspherical Factor for Each Substance

\begin{tabular}{lcccccc}
\hline Substance & $M\left(\mathrm{~kg} \cdot \mathrm{kmol}^{-1}\right)$ & $T_{\mathrm{c}}(\mathrm{K})$ & $p_{\mathrm{c}}(\mathrm{kPa})$ & $\rho_{\mathrm{c}}\left(\mathrm{kg} \cdot \mathrm{m}^{-3}\right)$ & $\omega$ & $\theta \times 10^{3}$ \\
\hline Argon & 39.948 & 150.69 & 4863 & 535.6 & 0.000 & 0.000 \\
Nitrogen & 28.013 & 126.19 & 3395 & 313.0 & 0.037 & 0.000 \\
Carbon Dioxide & 44.010 & 304.13 & 7377 & 467.6 & 0.225 & 0.238 \\
Ethane & 30.070 & 305.32 & 4872 & 206.0 & 0.099 & 0.114 \\
Pentafluoroethane & 120.020 & 339.17 & 3620 & 572.0 & 0.306 & 0.427 \\
1,1,1,2-Tetrafluoroethane & 102.030 & 374.18 & 4055 & 511.0 & 0.327 & 0.796 \\
1,1,1-Trifluoroethane & 84.041 & 346.30 & 3787 & 433.0 & 0.260 & 1.220 \\
1,1-Difluoroethane & 66.050 & 386.41 & 4516 & 368.0 & 0.275 & 1.422 \\
Trifluoromethane & 70.014 & 298.90 & 4810 & 540.0 & 0.265 & 1.524 \\
Difluoromethane & 52.020 & 351.26 & 5782 & 428.0 & 0.277 & 2.401 \\
Ammonia & 17.031 & 405.40 & 11345 & 232.0 & 0.256 & 2.025 \\
Water & 18.015 & 647.10 & 22050 & 325.0 & 0.344 & 3.950 \\
Methanol & 32.042 & 512.5 & 8080 & 263.0 & 0.560 & 3.721
\end{tabular}

with

$$
\begin{aligned}
& f_{\left(T_{\mathrm{r}}\right)}^{(0)}=a_{00}+a_{10} / T_{\mathrm{r}}^{3}+a_{20} / T_{\mathrm{r}}^{6}+a_{30} / T_{\mathrm{r}}^{11}, \\
& f_{\left(T_{\mathrm{r}}\right)}^{(1)}=a_{01}+a_{11} / T_{\mathrm{r}}^{3}+a_{21} / T_{\mathrm{r}}^{6}+a_{31} / T_{\mathrm{r}}^{11}, \\
& f_{\left(T_{\mathrm{r}}\right)}^{(2)}=a_{02}+a_{12} / T_{\mathrm{r}}^{3}+a_{22} / T_{\mathrm{r}}^{6}+a_{32} / T_{\mathrm{r}}^{11} .
\end{aligned}
$$

The parameters $a_{\mathrm{ij}}$ of Eq. (4), given in Table II, are determined by fitting the experimental data of the third virial coefficients of argon, carbon dioxide, pentafluoroethane (R125), 1,1,1,2-tetrafluoroethane (R134a), and water as simple nonpolar and polar substances. The coefficients $a_{\mathrm{ij}}$ are not dependent on specific substances and are expected to extend to a wider range of molecules. Furthermore, the method was also tested to compare the other nonpolar substances, ethane and nitrogen, and polar substances, 1,1,1-trifluoroethane (R143a), 1,1-difluoroethane (R152a), trifluoromethane (R23), difluoromethane (R32), ammonia, and methanol. The data mainly come from the compilation of virial coefficients by Dymond and Smith [27] and more recent literature sources [5-8, 28-49].

Table II. General Coefficients of Eq. (4)

\begin{tabular}{lccclcll}
\hline$a_{00}$ & 0.1623538 & $a_{10}$ & 0.3087440 & $a_{20}$ & -0.01790184 & $a_{30}$ & -0.02789157 \\
$a_{01}$ & -0.5390344 & $a_{11}$ & 1.783526 & $a_{21}$ & -1.055391 & $a_{31}$ & 0.09955867 \\
$a_{02}$ & 34.22804 & $a_{12}$ & -74.76559 & $a_{22}$ & 279.9220 & $a_{32}$ & -62.85431 \\
\hline
\end{tabular}




\section{COMPARISONS WITH AVAILABLE DATA AND EXISTING METHODS}

The present results compared with experimental data and existing methods have shown that the present method is more general to describe the various kinds of substances with reasonable accuracy under consideration of the data uncertainty of the third virial coefficient. A comparison of the present correlation and the correlations of Orbey and Vera [17] and of Weber [11] for nonpolar and polar substances displays the improvement of the SE-CSP to the CSP of Pitzer et al. [20, 21]. Because of the difficulties of determining the third virial coefficients, the data have generally suffered large uncertainties.

For the third virial coefficients of argon, nitrogen, carbon dioxide, and ethane, as representatives of nonpolar compounds, the results obtained with the present correlation are shown in Figs. 1 to 4 . It can be seen that our method is in agreement with the experimental data of Orbey and Vera [17] for all of these nonploar substances. Since the equation of Weber was established to represent small polar substances, it does not describe these

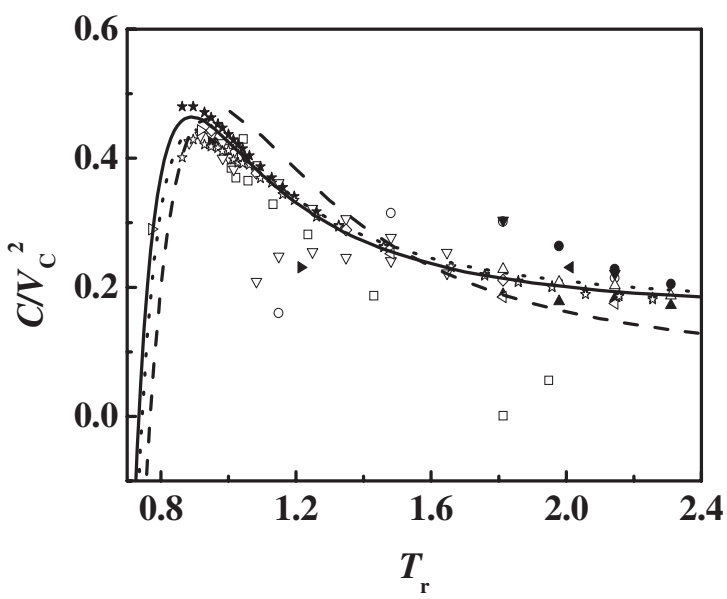

Fig. 1. Third virial coefficients of argon: ( $\cdots)$ Orbey and Vera [17]; (---) Weber [11]; (-) This work; ( $\square$ ) Onnes and Crommelin (1910) [27]; (O) Holborn and Otto (1925) [27]; (О) Tanner and Masson (1930) [27]; (A) Michels et al. (1949) [27]; $(\triangle)$ Whalley et al. (1953) [27]; ( $)$ Michels et al. (1958) [27]; ( $\nabla)$ Lecocq (1960) [27]; (灾) Crain and Sonntag (1966) [27]; $(\diamond)$ Kalfoglou and Miller

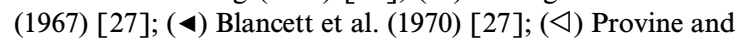

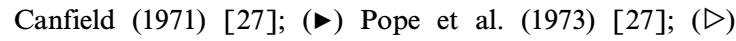
Gilgen et al. [28]; ( $\star$ Tegeler et al. [29]. 


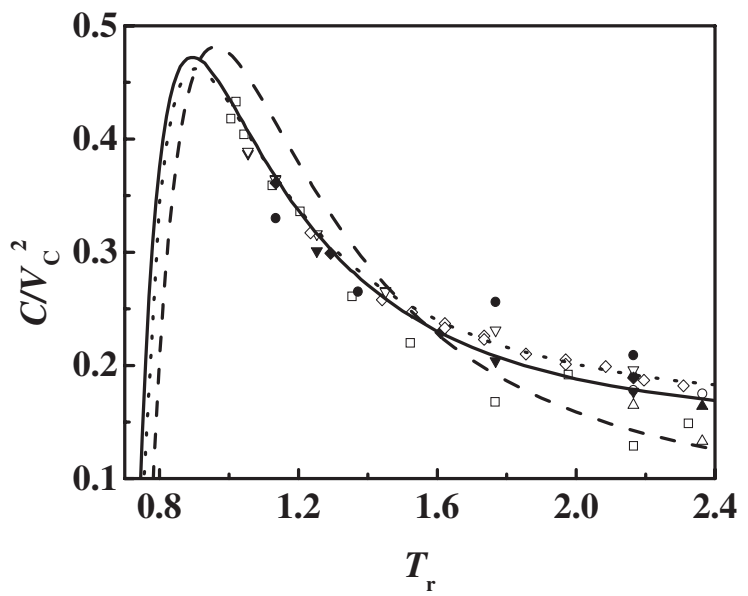

Fig. 2. Third virial coefficients of nitrogen: ( . . Orbey and Vera [17]; (---) Weber [11]; (-) This work; ( $\square)$ Onnes and van Urk (1924) [27]; (O) Holborn and Otto (1925) [27]; (O) Otto et al. (1934) [27]; (A) Michels et al. (1936) [27]; $(\triangle)$ Michels et al. (1951) [27]; ( $\mathbf{v})$ Canfield et al. (1963) [27]; $(\nabla)$ Hoover et al. (1964) [27]; ( ) Crain et al. (1966) [27]; $(\diamond)$ Roe and Saville (1972) [27].

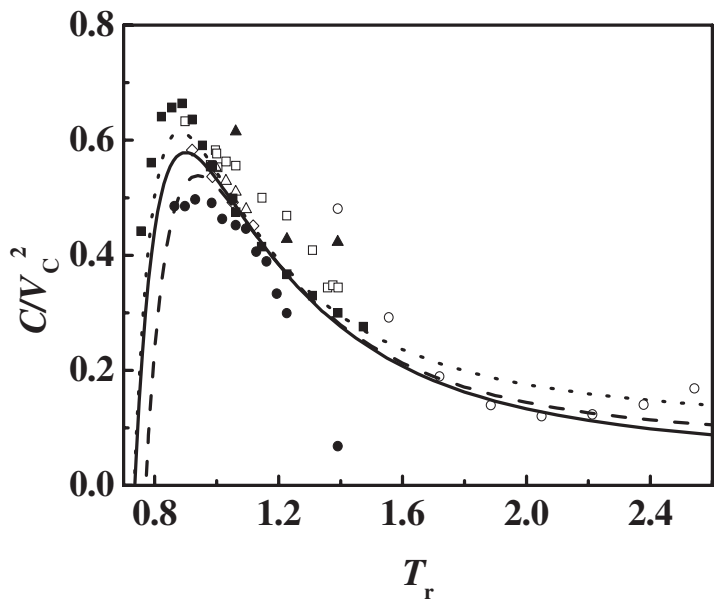

Fig. 3. Third virial coefficients of carbon dioxide: $(\cdots)$ Orbey and Vera [17]; (---) Weber [11]; (-) This work; ( $\square$ ) Michels and Michels (1935) [27]; (๑) Butcher and Dadson (1964) [27]; (○) Vukalovich and Masalov (1966) [27]; (ם) Holste et al. [30]; ( $\Delta$ ) Mallu et al. [31]; $(\triangle)$ McElroy et al. [32]; $(\diamond)$ Duschek et al. [33]. 


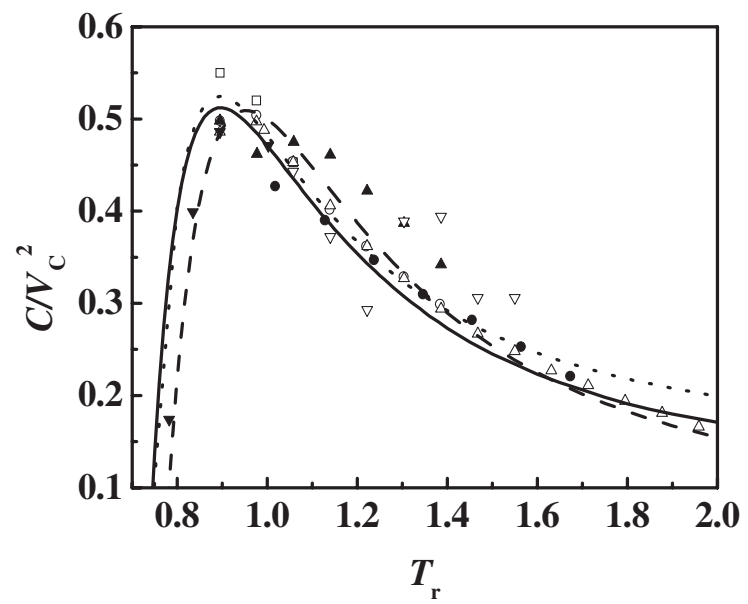

Fig. 4. Third virial coefficients of ethane: $(\cdots)$ Orbey and Vera [17]; (---) Weber [11]; (-) This work; ( $\square$ ) Michels and Nederbragt (1939) [27]; (О) Reamer et al. (1944) [27]; (○) Michels et al. (1954) $a$ [27]; ( $\Delta$ ) Michels et al. (1954) $b$ [27]; $(\triangle)$ Douslin and Harrison (1973) [27];

( $)$ Pope et al. (1973) [27]; ( $\nabla)$ Mansoorian et al. (1977) [27].

nonpolar substances well compared to the present method. From all of the comparisons, it can be seen that the SE-CSP method is suitable for nonpolar substances.

For polar substances, the results of three methods used to correlate the third virial coefficients are given in Figs. 5 to 13. The method of Orbey and Vera cannot well describe the third virial coefficients for strongly polar substances. Comparisons have shown that the Weber method is better to reproduce the derived and calculated data for some halogen-substituted methanes and ethanes, as can be seen from Figs. 5 to 10 for R143a, R152a, $\mathrm{R} 23$, and R32. We have compared the recommended compressibility factor values in the saturated vapor phase for R143a [50] and R32 [51] from the virial equation of state based on the extended corresponding-states method for the second virial coefficient [26] and third virial coefficient, Eqs. (3) and (4). It should be noted the calculated pressure in the saturated vapor phase appears to be higher than the actual pressure, which indicates that the third virial coefficients for these two fluorochlorocarbons obtained from our extended corresponding-states method are still higher than the true values in the region where the virial coefficients can work, although one can see that our present calculations for third virial coefficients of 


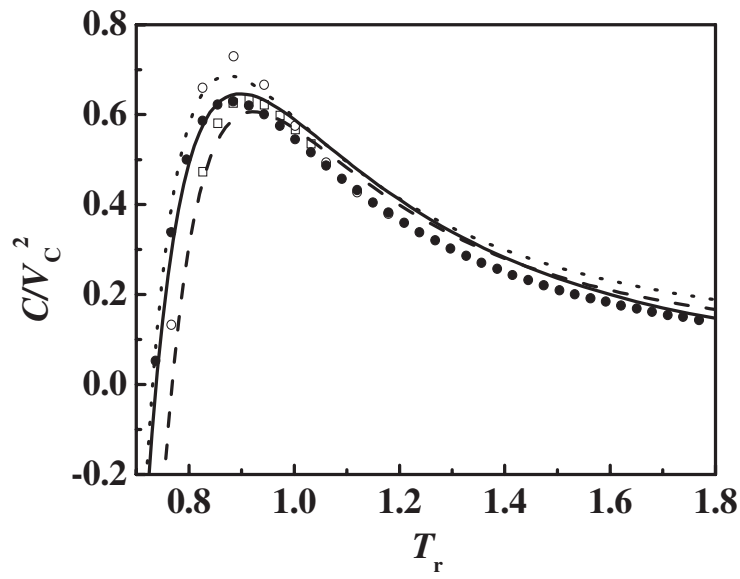

Fig. 5. Third virial coefficients of R125: ( ․) Orbey and Vera [17]; (---) Weber [11]; (-) This work; $(\square)$ Boyes and Weber [6]; (O) Gillis [7]; (O) Yokozeki et al. [8].

R143a and R32 are lower than those of Weber. If we believe that the vapor-phase density values are accurate for R143a [50] and R32 [51], it can be shown that the third virial coefficient of R143a and R32 probably have large errors. The discrepancy between our correlation and the correlation of Weber is generally large at low temperatures. Figures 11-13

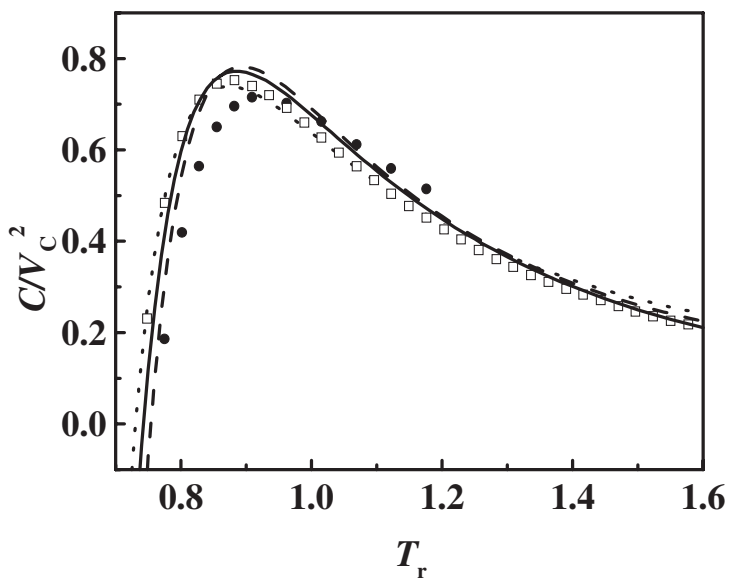

Fig. 6. Third virial coefficients of R134a: ( ...) Orbey and Vera [17]; (---) Weber [11]; (-) This work; Goodwin and Moldover [5]; ( $\square$ ) Yokozeki et al. [8]. 


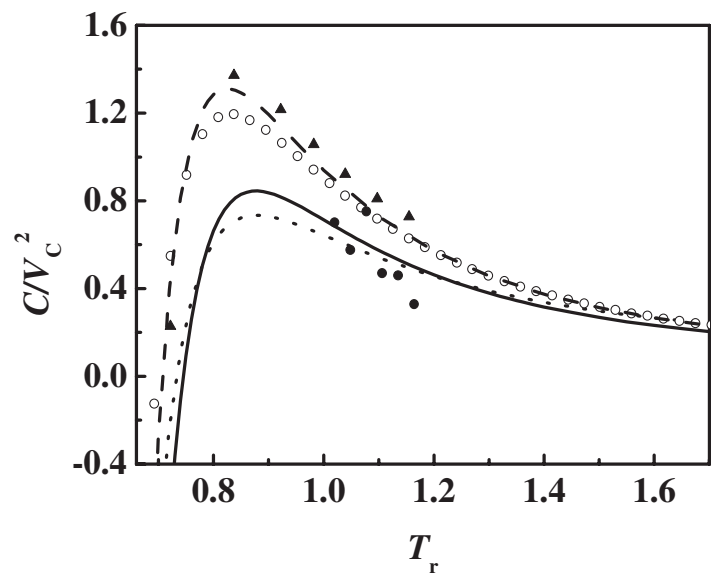

Fig. 7. Third virial coefficients of R143a: ( ...) Orbey and Vera [17]; (---) Weber [11]; (-) This work; (A) Gillis [7]; (○) Yokozeki et al. [8]; (○) Nakamura et al. [34].

show predictions of the third virial coefficients of highly nonspherical molecules, such as ammonia, water, and methanol, with the present method. It can be seen that the predictions of the present method are more reliable than that of Orbey and Vera and of Weber for these highly polar substances.

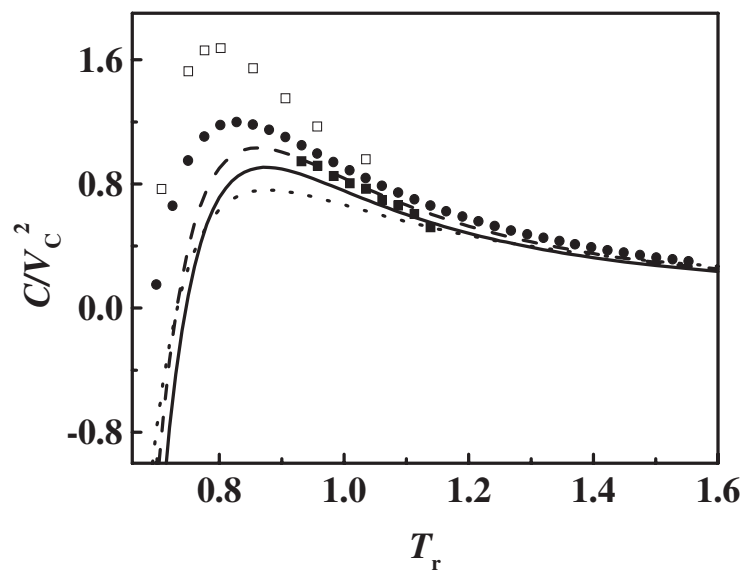

Fig. 8. Third virial coefficients of R152a: (...) Orbey and Vera [17]; (---) Weber [11]; (-) This work; ( $\square$ ) Gillis [7]; (O) Yokozeki et al. [8]; (ロ) Tamatsu et al. [35]. 


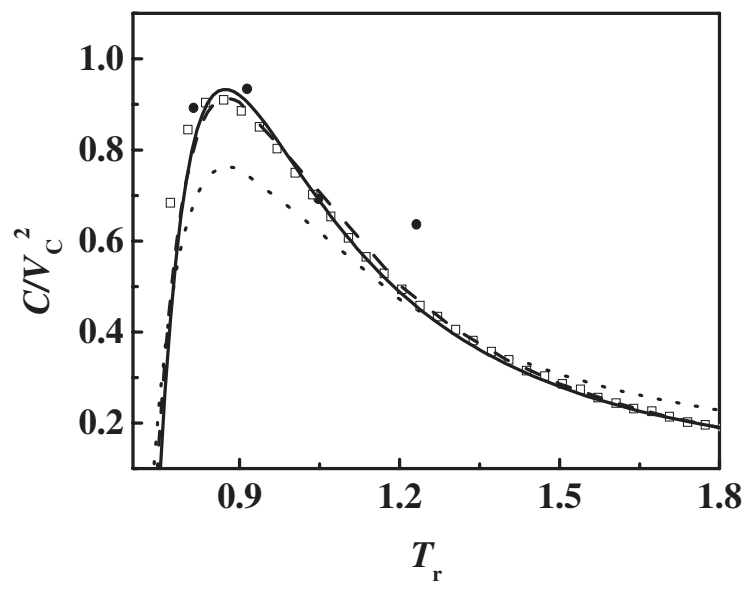

Fig. 9. Third virial coefficients of R23: ( ..) Orbey and Vera [17]; (---) Weber [11]; (-) This work; (○) Lange et al. (1970) [27]; ( $\square)$ Yokozeki et al. [8].

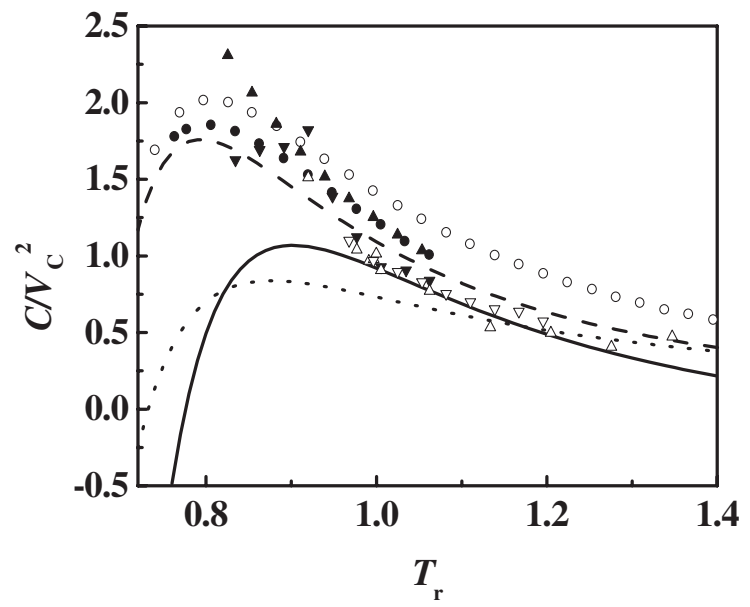

Fig. 10. Third virial coefficients of R32: ( . ) Orbey and Vera [17]; (---) Weber [11]; (-) This work; (○) Lange et al. (1970) [27]; ( $\square$ ) Yokozeki et al. [8]; ( $\Delta$ ) Defibaugh et al. [36]; ( $\mathbf{\nabla})$ Fu et al. [37]; (○) Zhang et al. [38]; $(\triangle)$ Kuznetsov et al. [39]; ( $\nabla)$ Sato et al. [40]. 


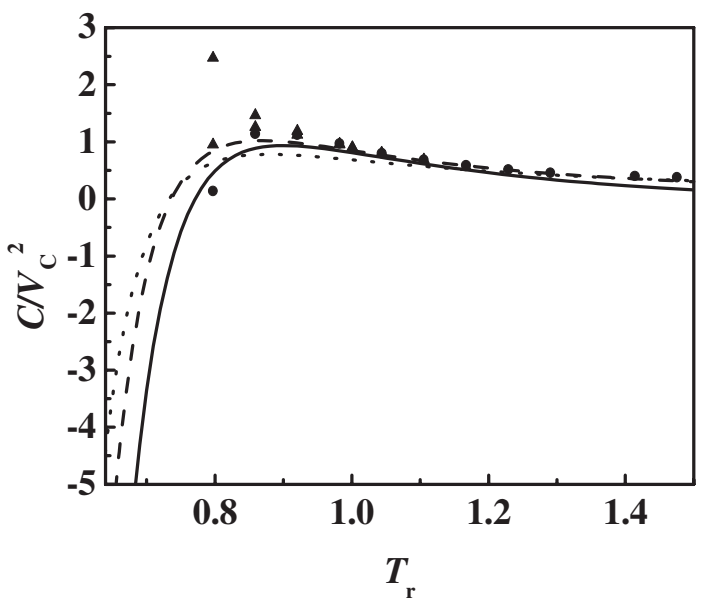

Fig. 11. Third virial coefficients of ammonia: ( $\cdots)$ Orbey and Vera [17]; (---) Weber [11]; (-) This

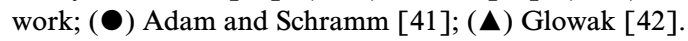

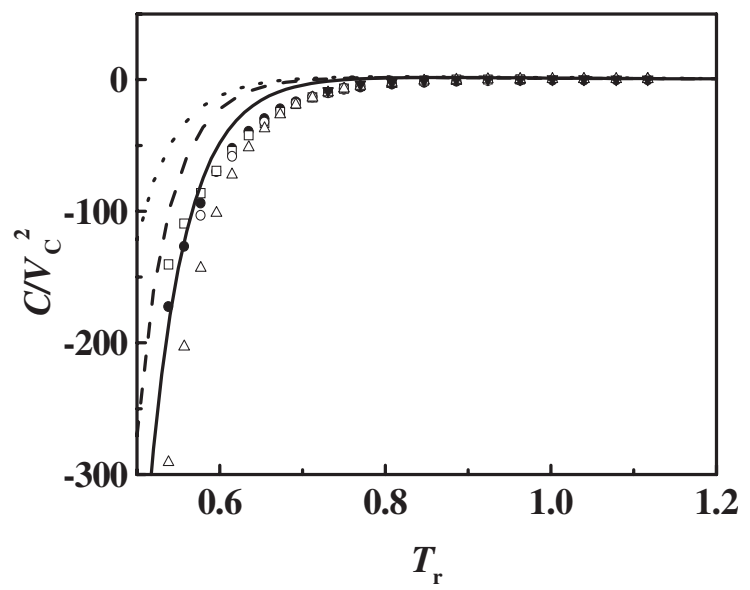

Fig. 12. Third virial coefficients of water: $(\cdots)$ Orbey and Vera [17]; (---) Weber [11]; (-) This work; ( - ) Vukalovich et al. (1967) [27]; ( $\diamond)$ Kell et al. (1968) [27]; (○) Haar et al. [43]; $(\triangle)$ Hill and MacMillan [44]; ( $\square$ ) Eubank et al. [45] (set II); (O) Eubank et al. [45] (set III). 


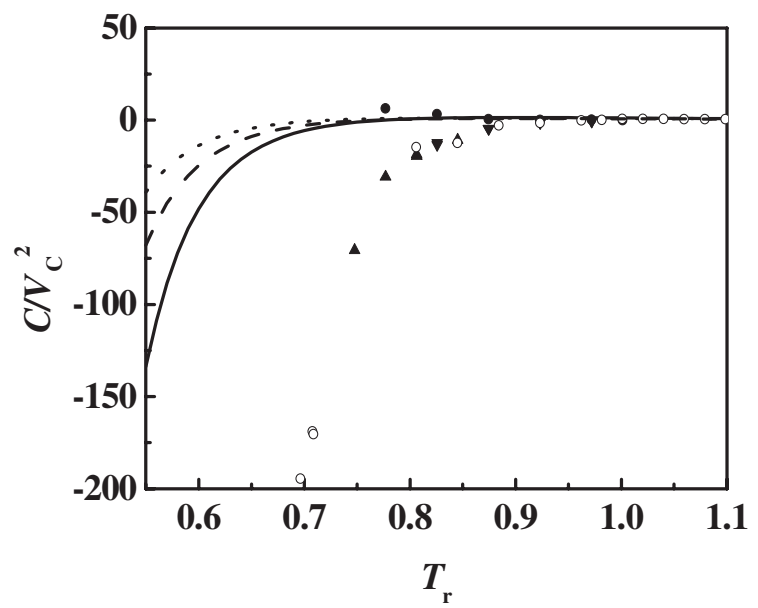

Fig. 13. Third virial coefficients of methanol: ( ...) Orbey and Vera [17]; (---) Weber [11]; (-) This work; (O) Bich et al. [46]; ( $\boldsymbol{\Delta})$ Shakhverdiev et al. [47]; ( $)$ Olf et al. [48]; (O) Kell and McLaurin [49].

\section{CONCLUSIONS}

The simple extended corresponding-states method presented here provides a simple and general method to correlate and predict the third virial coefficients of nonpolar and polar substances. Comparisons with experimental data and existing methods show that the correlation can be comparable to the method of Orbey and Vera for nonpolar gases and to the method of Weber for polar substances. The present correspondingstates correlation may be improved to further represent the experimental data when future measurement accuracies are improved.

\section{ACKNOWLEDGMENTS}

Financial support by the Foundation of Chinese Academy of Sciences and Departments of Personnel and of Education and, National Natural Science Foundation of China is appreciated. We are indebted to Professor G. Ali Mansoori at the University of Illinois at Chicago for his valuable comments.

\section{REFERENCES}

1. J. O. Hirschfelder, C. F. Curtis and R. B. Bird, in Molecular Theory of Gases and Liquids (Wiley, New York, 1954).

2. K. Kihara, Nippon-Sugaku-Busturigakaishi 17:11 (1943). 
3. W. H. Stockmayer, J. Chem. Phys. 9:398 (1941).

4. J. S. Rowlinson, J. Chem. Phys. 19:827 (1951).

5. A. R. H. Goodwin and M. R. Moldover, J. Chem. Phys. 93:2741 (1990).

6. S. J. Boyes and L. A. Weber, J. Chem. Thermodyn. 27:163 (1995).

7. K. A. Gillis, Int. J. Thermophys. 18:73 (1997).

8. A. Yokozeki, H. Sato, and K. Watanabe, Int. J. Thermophys. 19:89 (1998).

9. N. Van Nhu and F. Kohler, Ber. Bunsenges. Phys. Chem. 92:1129 (1988).

10. N. Van Nhu, G. A. Iglesias-Silva, and F. Kohler, Ber. Bunsenges. Phys. Chem. 93:526 (1989).

11. L. A.Weber, Int. J. Thermophys. 15:461 (1994).

12. L. A. Weber, Fluid Phase Equilib. 162:31 (1999).

13. P. L. Chueh and J. M. Prausnitz, AIChE J. 13:896 (1967).

14. G. A. Pope, P. S. Chappelear, and R. Kobayashi, J. Chem. Phys. 59:423 (1973).

15. R. De Santis and B. Grande, AIChE J. 25:931 (1979).

16. A. Bondi, in Physical Properties of Molecular Crystals, Liquids and Glasses (Wiley, New York, 1968).

17. H. Orbey and J. H. Vera, AIChE J. 29:107 (1983).

18. M. A. Bosse and R. Reich, Chem. Eng. Comm. 66:83 (1988).

19. E. M. Besher and J. Lielmezs, Thermochimica Acta 200:1 (1992).

20. K. S. Pitzer, D. Z. Lippmann, R. F. Curl, C. M. Huggins and D. E. Petersen, J. Am. Chem. Soc. 77:3433 (1955).

21. K. S. Pitzer and R. F. Curl, J. Am. Chem. Soc. 79:2369 (1957).

22. R. F. Curl and K. S. Pitzer, Ind. Eng. Chem. 50:265 (1958).

23. T. W. Leland and P. S. Chappelear, Ind. Eng. Chem. 60(7):15 (1968).

24. H. W. Xiang, J. Phys. Chem. Ref. Data 30:1161 (2001).

25. H. W. Xiang, Int. J. Thermophys. 22:919 (2001).

26. H. W. Xiang, Chem. Eng. Sci. 57:1439 (2002).

27. J. H. Dymond and E. B. Smith, in The Virial Coefficients of Pure Gases and Mixtures (Clarendon Press, Oxford, 1980).

28. R. Gilgen, R. Kleinrahm, and W. Wagner, J. Chem. Thermodyn. 26:383 (1994).

29. Ch. Tegeler, R. Span, and W. Wagner, J. Phys. Chem. Ref. Data 28:779 (1999).

30. J. C. Holste, K. R. Hall, P. T. Eubank, G. Esper, M. Q. Watson, W. Warowny, D. M. Bailey, J. G. Young and M. T. Bellomy, J. Chem. Thermodyn. 19:1233 (1987).

31. B. V. Mallu, G. Natarajan, and D. S. Viswanath, J. Chem. Thermodyn. 21:989 (1989).

32. P. J. McElroy, R. Battino, and M. K. Dowd, J. Chem. Thermodyn. 21:1287 (1989).

33. W. Duschek, R. Kleinrahm, and W. Wagner, J. Chem. Thermodyn. 22:827 (1990).

34. T. Tamatsu, T. Sato, H. Sato, and K. Watanabe, Int. J. Thermophys. 13:985 (1992).

35. S. Nakamura, K. Fujiwara, and M. Noguchi, J. Chem. Eng. Data 42:334 (1997).

36. D. R. Defibaugh, G. Morrison, and L. A. Weber, J. Chem. Eng. Data 39:333 (1994).

37. Y. D. Fu, L. Z. Han, and M. S. Zhu, Fluid Phase Equilib. 111:273 (1995).

38. H. L. Zhang, H. Sato, and K. Watanabe, J. Chem. Eng. Data 41:1401 (1996).

39. A. P. Kuznetsov and L. V. Los, Kholod. Tekh. Tekhnol. 14:64 (1972).

40. T. Sato, H. Sato, and K. Watanabe, J. Chem. Eng. Data 39:851 (1994).

41. G. Adam and B. Schramm, Ber. Bunsen-Ges. Phys. Chem. 81:442 (1977).

42. S. Glowak, Pol. J. Chem. 64:699 (1994).

43. L. Haar, J. S. Gallagher, and G. S. Kell, in NBS/NRC Stream Tables (Hemisphere, Washington, 1984).

44. P. G. Hill and R. D. C. MacMillan, Ind. Eng. Chem. Res. $27: 874$ (1988).

45. P. T. Eubank, L. L. Joffrion, M. R. Patel and W. Warowny, J. Chem. Thermodyn. 20:1009 (1988). 
46. E. Bich, R. Pietsch, and G. Opel, Z. Phys. Chem. 265:396 (1984).

47. A. N. Shakhverdiev, Y. M. Naziev, and D. T. Safarov, Teplofiz. Vys. Temp. 31:369 (1993).

48. G. Olf, A. Schnitzler, and J. Gaube, Fluid Phase Equilib. 49:49 (1989).

49. G. S. Kell and G. E. McLaurin, J. Chem. Phys. 51:4345 (1969).

50. R. Tillner-Roth and A. Yokozeki, J. Phys. Chem. Ref. Data 26:1273 (1997).

51. E. W. Lemmon and R. T Jacobsen, J. Phys. Chem. Ref. Data 29:521 (2000). 